\title{
Prospective serological and molecular cross-sectional study focusing on Bartonella and other blood-borne organisms in cats from Catalonia (Spain)
}

\author{
Alejandra Álvarez-Fernández ${ }^{1}$, Ricardo Maggi ${ }^{2}$, Gerard Eduard Martín-Valls ${ }^{3}$, Marta Baxarias ${ }^{1}$, \\ Edward Bealmear Breitschwerdt ${ }^{2}$ and Laia Solano-Gallego ${ }^{*^{*}}$ (1)
}

\begin{abstract}
Background: There is limited clinical or epidemiological knowledge regarding Bartonella infection in cats, and no serological studies have compared the presence of antibodies against different Bartonella species. Moreover, there are limited feline Bartonella studies investigating co-infections with other vector-borne pathogens and the associated risk factors. Therefore, the objective of this study was to investigate Bartonella spp. infections and co-infections with other pathogens in cats from Barcelona (Spain) based on serological and/or molecular techniques and to determine associated risk factors.

Methods: We studied colony and owned cats $(n=135)$. Sera were tested for Bartonella henselae-, Bartonella quintana-, and Bartonella koehlerae-specific antibodies using endpoint in-house immunofluorescence antibody assays, Bartonella real-time PCR (qPCR) and conventional PCR (CPCR) were performed. In addition, CPCR followed by DNA sequencing was performed for other pathogenic organisms (Anaplasma, Babesia, Cytauxzoon, Ehrlichia, Hepatozoon, hemotropic Mycoplasma, and Theileria spp.).

Results: From 135 cats studied, 80.7\% were seroreactive against at least one Bartonella species. Bartonella quintana, B. koehlerae, and B. henselae seroreactivity was $67.4,77.0$, and $80.7 \%$, respectively. Substantial to almost perfect serological agreement was found between the three Bartonella species. Colony cats were more likely to be Bartonella spp.-seroreactive than owned cats. Moreover, cats aged $\leq 2$ years were more likely to be Bartonella spp.-seroreactive. Bartonella spp. DNA was detected in the blood of $11.9 \%(n=16)$ of cats. Cats were infected with B. henselae $(n=12)$, B. clarridgeiae $(n=3)$, and B. koehlerae $(n=1)$. Mycoplasma spp. DNA was amplified from $14 \%(n=19)$ of cat blood specimens. Cats were infected with Mycoplasma haemofelis $(n=8)$, Candidatus M. haemominutum $(n=6)$, Candidatus Mycoplasma turicensis $(n=4)$, and Mycoplasma wenyonii $(n=1)$. Anaplasma, Babesia, Cytauxzoon, Ehrlichia spp., Hepatozoon, and Theileria spp. DNA was not amplified from any blood sample. Of the 16 Bartonella spp.-infected cats based on PCR results, six (37\%) were co-infected with Mycoplasma spp.
\end{abstract}

Conclusions: Bartonella spp. and hemoplasma infections are prevalent in cats from the Barcelona area, whereas infection with Anaplasma spp., Babesia, Cytauxzoon, Ehrlichia spp., Hepatozoon, and Theileria infections were not

*Correspondence: laia.solano@uab.cat

${ }^{1}$ Department of Animal Medicine and Surgery, Facultat de Veterinària,

Universitat Autònoma de Barcelona, Cerdanyola del Valles, Spain

Full list of author information is available at the end of the article permits use, sharing, adaptation, distribution and reproduction in any medium or format, as long as you give appropriate credit to the original author(s) and the source, provide a link to the Creative Commons licence, and indicate if changes were made. The images or other third party material in this article are included in the article's Creative Commons licence, unless indicated otherwise in a credit line to the material. If material is not included in the article's Creative Commons licence and your intended use is not permitted by statutory regulation or exceeds the permitted use, you will need to obtain permission directly from the copyright holder. To view a copy of this licence, visit http://creativecommons.org/licenses/by/4.0/. The Creative Commons Public Domain Dedication waiver (http://creativeco mmons.org/publicdomain/zero/1.0/) applies to the data made available in this article, unless otherwise stated in a credit line to the data. 
detected. Co-infection with hemotropic Mycoplasma appears to be common in Bartonella-infected cats. To our knowledge, this study is the first to document M. wenyonii is infection in cats.

Keywords: Bartonellosis, Hemotropic Mycoplasma, Mycoplasma wenyonii, Ehrlichia, Anaplasma, Piroplasma, Co-infection, Cats, Spain

\section{Background}

Bartonellosis, caused by Bartonella spp. parasites, is a vector-borne infectious disease that is currently considered an emerging zoonosis [1]. More than 40 Bartonella species that are adapted to infect a broad spectrum of reservoir mammalian hosts, including cats, are described in the literature [2,3]. Transmission to cats is mainly by flea feces, potentially ticks, and scratches and bites between hosts. The cat has been described as the main reservoir for Bartonella henselae, Bartonella clarridgeiae and Bartonella koehlerae [4]. However, cats can be sporadically infected with two other zoonotic Bartonella species: Bartonella quintana $[5,6]$ and Bartonella vinsonii subsp. berkhoffii [7].

The spectrum of disease manifestations associated with Bartonella spp. infections in cats continues to expand [8], despite the fact that it is not easy to demonstrate an association between clinical signs, laboratory abnormalities, and Bartonella spp. infection [9, 10]. This factor is primarily due to the long duration of relapsing bacteremia and the high percentage of infected healthy cats in endemic areas $[3,11]$. Although the majority of acute infections caused by Bartonella spp. are thought to be self-limiting in cats [12], persistent infections can be associated with a wide variety of clinical signs and abnormalities. These manifestations in cats can range from intra- or extra-erythrocytic subclinical bacteremia to fever of unknown origin, lymphadenomegaly, endocarditis, myocarditis, ocular disease (neuroretinitis, uveitis), skin inflammation, and other less common disease manifestations [13, 14]. Various factors allow Bartonella spp. to persist in the blood of hosts, causing a chronic intravascular and endotheliotropic infection that can ultimately result in the appearance of nonspecific or specific clinical manifestations. Factors that influence symptomatology include virulence differences among Bartonella spp. and strains, the mode of transmission, differences in the host immune response and clinical status (comorbidities), concurrent infectious or noninfectious diseases, bacterial load, therapeutic- or infection-induced immunosuppression, and malnutrition $[15,16]$.

Due to the abovementioned factors, establishing disease causation or a diagnosis of Bartonella spp. infections can be clinically challenging, particularly in cats. There are no available diagnostic techniques whose negative result guarantees the absence of infection [3]. Under this premise, infection can be confirmed only by positive diagnostic test results derived from molecular modalities, such as conventional (cPCR) or real-time PCR (qPCR), ideally accompanied by DNA sequencing, or the isolation and identification of the bacteria by enrichment culture, rather than exposure $[17,18]$. In addition to technical limitations inherent in culture and PCR diagnostic techniques, Bartonella may not be present in sufficient quantities in the blood at the time of specimen collection to be detected. As an example, Bartonella DNA was amplified from fresh frozen tissues of dogs with hemangiosarcoma, where qPCR from blood failed to amplify bacterial DNA [19]. Thus, choosing the correct sample for culture or PCR testing could also be critical for the definitive diagnosis of bartonellosis [19].

Indirect immunofluorescence assays (IFA) are the most frequently used serological technique for the detection of antibodies against Bartonella spp. [2023], but other serological assays are available, such as enzyme-linked immunosorbent assay (ELISA) and western immunoblot [12, 24]. A serological negative result does not ensure that a cat is not infected with a Bartonella sp., and a positive result only documents the presence of antibodies against the pathogen, but does not confirm infection. Although technically challenging and more expensive than selecting individual tests, considering a combination of diagnostic techniques and optimal specimen types in conjunction with the correct interpretation of the results is likely a good strategy to increase diagnostic success in cats with suspected bartonellosis [3, 19].

Bartonella spp. epidemiological studies involving cats, carried out in many parts of the world, have documented substantial differences in prevalence from one area to another $[3,25]$. In Europe, many studies including various cat populations have reported seroprevalence ranging from 0 to $71.4 \%$ and molecular prevalence rates ranging from 0 to $83.5 \%$ [3, 26, 27]. In Europe, including Spain, clinical and epidemiological knowledge regarding Bartonella infection in cats remains limited. Furthermore, there are no serological studies comparing the presence of antibodies against different Bartonella species in cats, and only a few molecular studies have assayed bacteremia in cats $[28,29]$. In addition, there are limited feline Bartonella studies that investigated 
co-infections with other vector-borne pathogens and the associated risk factors $[29,30]$. The objective of this study was to test cat serum samples for the presence of antibodies against $B$. henselae, $B$. quintana, and $B$. koehlerae antigens. To assess for co-infections, blood samples were tested by PCR for Anaplasma spp., Bartonella spp., Ehrlichia spp., and hemotropic Mycoplasma spp. and using primers that amplified Babesia, Cytauxzoon, Hepatozoon, and Theileria spp.

\section{Methods}

A prospective cross-sectional study, conducted between 2017 and 2019 in cats from Barcelona province (Spain), was designed to investigate Bartonella spp. seroprevalence and bacteremia prevalence using $\mathrm{QPCR}$ and $\mathrm{CPCR}$, with all DNA amplicons sequenced to confirm species identity. In addition, co-infection with other feline vector-borne pathogens was assessed by CPCR testing.

\section{Cats and specimen collection}

A total of 117 blood specimens from apparently healthy cats and 18 blood specimens from sick cats were collected by venipuncture. A general physical examination was performed in all cats. A clinical questionnaire was completed for each cat including information about age, sex, colony origin or owned pet, breed, weight, clinical history, travel history, health status (sick versus healthy), exposure to fleas and/or ticks or bites, and the use of acaricide products. In most cases $(n=110)$, the blood specimens were obtained under anesthesia during a neutering procedure. A signed consent form was obtained from the owners or by the colony origin person in charge of the cats.

Approximately $8-10 \mathrm{ml}$ of peripheral blood was collected by jugular or cephalic venipuncture from each cat at the time of enrollment. Two milliliters was collected into an EDTA-anticoagulant tube for DNA extraction, and 4-6 ml was injected into serum separator tubes with clot accelerator and granule serum separator for serology. Samples were subsequently stored at $-80{ }^{\circ} \mathrm{C}$ until testing.

\section{Bartonella IFA serological testing}

For all 135 cats, three IFAs were used to detect serum antibodies directed against three Bartonella species (B. henselae, B. quintana, and B. koehlerae antigens) as described previously [31, 32]. Briefly, to obtain antigens for IFA testing, $B$. henselae SA2+ (feline origin Missy S 95 FO-099), B. quintana cynomolgus monkey origin 11-MO-01 (China/Pfizer), and B. koehlerae (originally from blood of Trillium B, feline) were passed from agargrown cultures of each organism into DH82 (a continuous canine histiocytic cell line) cultures. For each antigen, infected cell cultures were spotted onto 30-well
Teflon-coated slides (Cel-Line/Thermo Scientific), airdried, acetone-fixed, and stored frozen. Serum samples were diluted in phosphate-buffered saline (PBS) solution containing $1 \%$ normal goat serum, $0.05 \%$ Tween 20 , and $0.5 \%$ powdered nonfat dry milk (Bio-Rad, Hercules, CA, USA) to block nonspecific antigen binding sites. Cat sera were further tested with twofold dilutions out to a final dilution of 1:16384, and $10 \mu \mathrm{l}$ of each serum dilution was applied per well. Previously tested positive and negative controls were selected and added in each slide. The slides were incubated for $30 \mathrm{~min}$ at $37{ }^{\circ} \mathrm{C}$ and then washed with PBS under moderate agitation for an additional $30 \mathrm{~min}$. Once slides were dry, $10 \mu \mathrm{l}$ of fluorescein-conjugated goat anti-cat immunoglobulin G (IgG) (MP Biomedicals) at a dilution of 1:100 was added into each well. The slides were incubated for another $30 \mathrm{~min}$ at $37^{\circ} \mathrm{C}$ in the dark to protect the photosensitive conjugate. The washing procedure described above was repeated, adding a few drops of Tween 20 (Sigma-Aldrich). After the last washing procedure, some drops of antifade mounting medium (Vectashield, Vector Labs, Burlingame, CA, USA) were added on the cover slips. The slides were evaluated using a fluorescence microscope (Leica DM6000 B; Leica Microsystems, Wetzlar, Germany) at $\times 200$ and $\times 400$ magnification, and each well was compared to the fluorescence pattern seen in the positive and negative controls. To avoid confusion with possible nonspecific binding found at low dilutions, a cutoff of 1:64 was selected as a seroreactive antibody titer [31,32]. Antibody titer results were classified as low seroreactivity from 1:64 to 1:512 and high seroreactivity $>1: 512$ for comparative analyses [32].

\section{Blood DNA purification}

EDTA tubes were centrifuged at $1300 \times g$ for $5 \mathrm{~min}$. Plasma was obtained for further studies and the cellular pellet was used for DNA extraction. Total DNA was extracted from blood cell pellets in 110 samples and from EDTA whole blood in 25 samples using the DNA Gene extraction kit (Sigma-Aldrich) following the manufacturer's instructions, with slight modifications. Forty microliters of proteinase $\mathrm{K}$ solution was added to all samples. Four hundred microliters of whole blood was used for all sample DNA extractions. The other steps were performed as described previously [33]. Distilled water was used as a negative control for all DNA extractions.

\section{Conventional and quantitative real-time PCR analysis}

DNA extracted from each blood sample was screened for the presence of Bartonella spp. using CPCR and qPCR, 
and for Ehrlichia spp., Anaplasma spp., piroplasmids, and hemotropic Mycoplasma spp. DNA using only cPCR. The primers used for $\mathrm{CPCR}$ and qPCR to establish species strain identification by amplicon product size or melting temperature, respectively, are summarized in Table 1.

\section{Conventional PCR analysis}

Amplification was performed in a $25-\mu \mathrm{l}$ final volume reaction containing $12.5 \mu \mathrm{l}$ of Taq-Ex ${ }^{\circledR}$ Premix (Fisher Scientific), $0.2 \mu \mathrm{l}$ of $100 \mu \mathrm{M}$ of each forward and reverse primer (Roche Diagnostics, Basel, Switzerland) $7.1 \mu \mathrm{l}$ of distilled $\mathrm{H}_{2} \mathrm{O}$, and $5 \mu \mathrm{l}$ of DNA from each sample tested. PCR negative controls were prepared by adding distilled $\mathrm{H}_{2} \mathrm{O}$. Positive controls were used in each reaction and were prepared by serial dilution (using cat blood DNA) of genomic DNA from each pathogen down to $0.001 \mathrm{pg} /$ $\mu \mathrm{l}$ (equivalent to 0.5 bacteria/ $\mu \mathrm{l}$ ). Conventional PCR was performed in a VeritiPro Thermal Cycler (Applied Biosystems, Waltham, MA, USA) under the following conditions: a single hot-start cycle at $95{ }^{\circ} \mathrm{C}$ for 2 min followed by 55 cycles of denaturing at $94{ }^{\circ} \mathrm{C}$ for $15 \mathrm{~s}$, annealing at $66{ }^{\circ} \mathrm{C}$ for $15 \mathrm{~s}$, and extension at $72{ }^{\circ} \mathrm{C}$ for $18 \mathrm{~s}$. Amplification was completed by an additional cycle at $72{ }^{\circ} \mathrm{C}$ for $1 \mathrm{~min}$, and products were analyzed by $1.5 \%$ agarose gel electrophoresis with detection using ethidium bromide under ultraviolet light.

\section{Real-time $P C R$ analysis}

Bartonella spp. qPCR was performed using a 7500 Fast Dx Real-Time PCR instrument (Applied Biosystems ${ }^{\mathrm{TM}}$ ) in $25-\mu \mathrm{l}$ final volume reactions. Master mix was prepared using $12.5 \mu \mathrm{l}$ of buffer and $1 \mu \mathrm{l}$ of enzyme mix (AgPathID $^{\mathrm{TM}}$ One-Step RT-PCR Reagents, Applied Biosystems $\left.{ }^{\mathrm{TM}}\right)$, $5.9 \mu \mathrm{l}$ of $\mathrm{H} 2 \mathrm{O}, 0.2 \mu \mathrm{l}$ of $100 \mu \mathrm{M}$ of fluorescent probe, and
$0.2 \mu \mathrm{l}$ of $100 \mu \mathrm{M}$ of each primer (Roche Diagnostics). PCR testing was carried out using $5 \mu$ of DNA. PCR negative and positive controls were prepared as described for cPCR. Real-time PCR conditions were as follows: a single hot-start cycle at $95^{\circ} \mathrm{C}$ for 3 min followed by 44 cycles of denaturing at $94{ }^{\circ} \mathrm{C}$ for $10 \mathrm{~s}, 10 \mathrm{~s}$ of annealing at $66^{\circ} \mathrm{C}$, and extension at $72{ }^{\circ} \mathrm{C}$ for $10 \mathrm{~s}$. When present, Bartonella spp. amplicons were detected by fluorescence readings at the appropriate wavelength [19].

\section{Sequencing of positive PCR amplicons}

The molecular characterization of Bartonella and hemotropic Mycoplasma spp., as well as the confirmation of $\mathrm{CPCR}$ and $\mathrm{GPCR}$ positive results, was performed by Sanger sequencing of $\mathrm{CPCR}$ and $\mathrm{qPCR}$ amplicons, followed by chromatographic evaluation and sequence alignment. For bacterial species identification, DNA sequences were analyzed by comparing similarity with other sequenced bacteria deposited in the GenBank database using the Basic Local Alignment Search Tool (BLAST). Only PCR results confirmed by sequencing were considered positive in this study.

\section{Statistical analysis}

A descriptive analysis was carried out for the data from each cat along with a comparative analysis according to the IFA and PCR results. Frequency analysis was performed for age, sex, colony/owned, ectoparasites, health status, and three Bartonella spp. IFA, cPCR, and qPCR results. Comparative analysis of categorical data was performed using the Chi-square test or Fisher's exact test. The kappa ( $\mathrm{k}$ ) statistic was used to assess the degree of (inter-rater) agreement between IFAs performed against three Bartonella species. The Shapiro-Wilk test was

Table 1 Target gene employed, size in base pairs of amplicons and CPCR and qPCR primer sequences used

\begin{tabular}{|c|c|c|c|}
\hline Target gene & $\begin{array}{l}\text { Size in base } \\
\text { pairs (bp) }\end{array}$ & Primer names and sequences & References \\
\hline \multicolumn{4}{|l|}{ Conventional PCR } \\
\hline $\begin{array}{l}\text { Bartonella spp. } \\
\text { 16S-23S ITS }\end{array}$ & $500-680 \mathrm{bp}$ & $\begin{array}{l}\text { BspplTS325s: 5' CTTCAGATGATGATCCCAAGCCTTTGGCG 3' } \\
\text { BspplTS1100as: 5' GAACCGACGACCCCCTGCTTGCAAAGCA 3' }\end{array}$ & [19] \\
\hline $\begin{array}{l}\text { Mycoplasma spp. (hemotropic group) } \\
16 \mathrm{~S} \text { rRNA }\end{array}$ & $588 \mathrm{bp}$ & $\begin{array}{l}\text { Myco16S-322 s 5' GCCCATATTCCTACGGGAAGCAGCAGT } 3^{\prime} \\
\text { Myco16S-938as 5' CTCCACCACTTGTTCAGGTCCCCGTC } 3^{\prime}\end{array}$ & [19] \\
\hline $\begin{array}{l}\text { Anaplasma or Ehrlichia } \\
16 \mathrm{~S} \text { rRNA }\end{array}$ & $420 \mathrm{bp}$ & $\begin{array}{l}\text { GEPs } 5^{\prime} \text { CTGGCGGCAAGCYTAACACATGCAAGTCGAACGGA } 3^{\prime} \\
\text { GEPr 5' CTTCTTCTRTRGGTACCGTCATTATCTTCCCYAYTG } 3^{\prime}\end{array}$ & [33] \\
\hline $\begin{array}{l}\text { Babesia, Cytauxzoon, Hepatozoon, and } \\
\text { Theileria spp. } \\
18 \text { rRNA }\end{array}$ & $663 \mathrm{bp}$ & $\begin{array}{l}\text { Piro 18S-144 s 5' ACCGTGCTAATTGTAGGGCTAATACA 3' } \\
\text { Piroplasma18S-722as 5' GAATGCCCCCAACCGTTCCTATTAAC 3' }\end{array}$ & [19] \\
\hline \multicolumn{4}{|l|}{ Real-time PCR } \\
\hline $\begin{array}{l}\text { Bartonella spp. } \\
\text { 16S-23S ITS }\end{array}$ & $200-231 \mathrm{bp}$ & $\begin{array}{l}\text { BspplTS325s: 5' CTTCAGATGATGATCCCAAGCCTTYTGGCG 3' } \\
\text { BspplTS543as: 5' TAAAYTGGTGGGCCTGGGAGGACTTG 3' } \\
\text { Probe BspplTS500: 5' FAM-GTTAGAGCGCGCGC TTGATAAG_IABkFQ 3' }\end{array}$ & [34] \\
\hline
\end{tabular}


performed to detect the normality of the distribution of the samples. A $P$-value $<0.05$ was considered statistically significant. Statistical analyses were performed using the $\mathrm{R}$ i386 version 3.3.1 ( $\mathrm{R}$ Development Core Team) and the DeduceR version 1.7-16 (DeduceR: A data Analysis GUI for R) software programs for Windows.

\section{Results}

\section{Cat description}

All cats sampled were European domestic shorthairs. Seventy-five of 135 cats $(55.5 \%)$ were female and 60 (44.5\%) were male. Only one female and two males were intact. All remaining cats were neutered. Cat age ranged from 4 months to 7 years, with a median age of 1.2 years. Cats $\leq 2$ years old were considered young cats and $>2$ years old were considered old cats. Fifty-eight percent (79/135) were colony cats and 41.5\% (56/135) were owned pet cats. A recent history of tick exposure or flea infestation was reported in $81.5 \%(110 / 135)$, whereas $18.5 \%(25 / 135)$ were flea- or tick-infested at the time of blood collection, including 23 colony cats and two owned pet cats. Colony cats were more likely to have a recent history of ectoparasites (100\%) compared to owned cats (3.6\%) (Fisher's exact test: $P<0.001, \mathrm{OR}=3466.2,95 \%$ confidence interval $[\mathrm{CI}]=163.2-73,624.6)$. Routine treatment with ectoparasiticides was reported for $18.5 \%$ $(25 / 135)$ of the cats. One hundred and seventeen cats (86.7\%) were clinically healthy, and $18(13.3 \%)$ cats had clinical signs at the time of sampling. Gingivitis was the most frequent clinical sign, found in $55.6 \%$ (10 of 18 , 95\% $\mathrm{CI}=32.6-78.5 \%)$ of the sick cats).

\section{Bartonella IFA in cat serum samples}

Considering antibody titers $\geq 1: 64,80.7 \%$ (109 of $135,95 \%$ $\mathrm{CI}=74.1-87.4 \%)$ of the cats were seroreactive against at least one Bartonella sp. antigen. Bartonella henselae, $B$. quintana, and B. koehlerae seroreactivity was $80.7 \%$ (109 of $135,95 \% \mathrm{CI}=74.1-87.4 \%$ ), $67.4 \%$ (91 of $135,95 \%$ $\mathrm{CI}=59.5-75.3 \%)$, and $77 \%(104$ of $135,95 \% \mathrm{CI}=69.9-$ $84.1 \%)$, respectively. Eighty-eight of 109 cats (80.7\%, 95\% CI $=73.3-88.1 \%$ ) were seroreactive against all three Bartonella spp. antigens, 32 cats $(29.3 \%, 95 \% \mathrm{CI}=20.8-$ $37.9 \%)$ were seroreactive against two Bartonella species, and five cats $(4.6 \%, 95 \% \mathrm{CI}=0.7-8.5 \%)$ were seroreactive against one Bartonella species. Interestingly, all cats that were seroreactive against $B$. koehlerae or $B$. quintana antigens were also seroreactive against $B$. henselae IFA antigens. Five cats had antibodies against $B$. henselae but were not seroreactive to the other two Bartonella spp. Kappa agreement analysis between Bartonella spp. IFA is summarized in Table 2. Cats seroreactive against B. quintan $a$ and $B$. koehlerae antigens were more likely to be $B$. henselae-seroreactive $(100 \%)$ than seronegative (Fisher's exact test: $P<0.001, \mathrm{OR}=262.9,95 \% \mathrm{CI}=15.3-4515.9$ and $\mathrm{OR}=1081.6,95 \% \mathrm{CI}=57.3-20,432.6)$. The serum IFA geometric mean antibody titer for $B$. henselae, $B$. quintana, and $B$. koehlerae antigens was 1:2050, 1:1028, and $1: 1460$, respectively. The maximum titer was $1: 16384$ for $B$. henselae and 1:8192 for B. quintana and B. koehlerae. The frequency of seronegative, low seroreactive, and high seroreactive antibody titers for the three Bartonella antigens studied is graphically displayed in Fig. 1.

When IFA results were compared with data collected from each cat, we found that colony cats were more likely to be Bartonella spp. (100\%)-seroreactive than owned pet cats (53\%) (Fisher's exact test: $P<0.001, O R=136.9$, $95 \% \mathrm{CI}=8-2319.8)$. Cats with a recent history of tick and flea infestation were more likely to be Bartonella spp. (99\%)-seroreactive (Fisher's exact test: $P<0.001$, $\mathrm{OR}=5450,95 \% \mathrm{CI}=177.8-167,014.7)$ when compared with non-infested cats. Cats with ectoparasites were more likely to be $B$. henselae-seroreactive (100\%) (Fisher's exact test: $P=0.001, \mathrm{OR}=15.5,95 \% \mathrm{CI}=0.9-263.2)$, $B$. koehlerae-seroreactive (100\%) (Fisher's exact test: $P=0.004, \mathrm{OR}=19.6,95 \% \mathrm{CI}=1.2-332.5)$, and $B$. quintana-seroreactive (84\%) (Fisher's exact test: $P=0.05$, $\mathrm{OR}=3,95 \% \mathrm{CI}=1-9.4)$. Cats $\leq 2$ years old were more likely to be Bartonella spp.-seroreactive (91.5\%) than cats $>2$ years old (41.4\%) (Chi-square test: $X^{2}=36.8$, $d f=1, P<0.001)$. Of the 109 cats that were seroreactive against any Bartonella species tested, 17 cats were sick (15.6\%, 95\% CI $=8.8-22.4 \%)$, whereas the remaining cats were clinically healthy. There was no statistical difference associated with serology and health status. No further significant associations were found.

Table 2 Comparison of agreement between IFAs performed against three Bartonella species

\begin{tabular}{lll}
\hline Test pair & $\mathrm{k} \pm \mathrm{SE}$ & $\mathrm{kinterpretation}^{\mathrm{a}}$ \\
\hline B. henselae IFA versus B. quintana IFA & $0.661 \pm 0.070$ & Substantial agreement \\
B. henselae IFA versus B. koehlerae IFA & $0.889 \pm 0.048$ & Almost perfect agreement \\
B. quintana IFA versus B. koehlerae IFA & $0.726 \pm 0.065$ & Substantial agreement \\
\hline
\end{tabular}

${ }^{a}$ The interpretation for each $\mathrm{k}$ value is shown in the final column according to the following scale: $\leq 0$, no agreement; $0.01-0.20$, none to slight; $0.21-0.40$, fair; $0.41-$ 0.60 , moderate; $0.61-0.80$, substantial; and $0.81-1.00$, almost perfect agreement. IFA, immunofluorescence antibody assay; $\mathrm{k}$, Cohen's kappa value; SE, standard error 


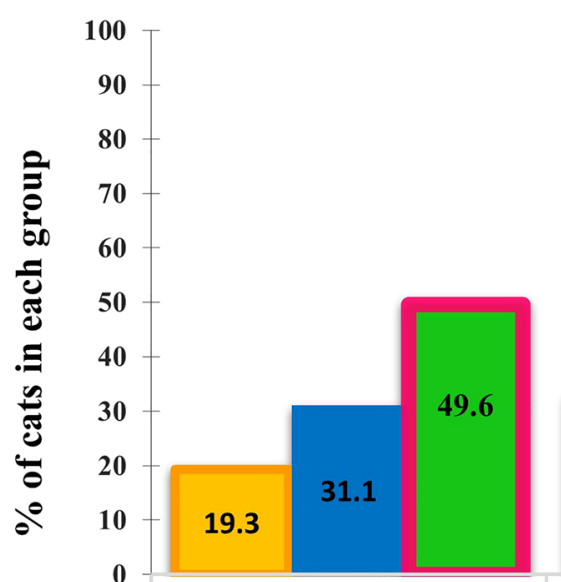

B. henselae

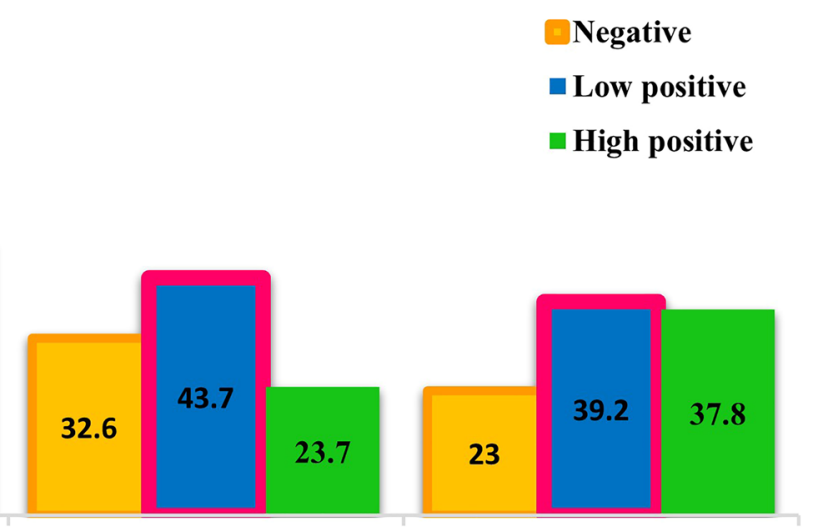

B. quintana

B. koehlerae

\section{Bartonella spp. antibodies tested}

Fig. 1 Frequencies of negative, low seroreactive, and high seroreactive by means of IFA for the three Bartonella spp. antigens studied. Bartonella spp. antibody titers were classified as low seroreactive from 1:64 to 1:512 and high seroreactive $>512$. The most prevalent group is boxed in pink for each Bartonella sp.

\section{PCR and sequencing}

Bartonella spp. DNA was amplified from the blood of $11.9 \%$ ( 16 of $135,95 \% \mathrm{CI}=6.4-17.3 \%$ ) of the cats using cPCR or qPCR. Based on DNA sequence alignments, cats were infected with $B$. henselae $(n=12), B$. clarridgeiae $(n=3)$, or $B$. koehlerae $(n=1)$. From 16 positive cats, Bartonella DNA was amplified using cPCR in 10 cases (Table 3 ) and using qPCR in eight cases (Table 4). Bartonella DNA was amplified by both cPCR and qPCR in only two of 16 cats. Based on PCR testing, $81.3 \%(95 \% \mathrm{CI}=62.1-100.4 \%)$ of bacteremic cats originated from a colony and were $\leq 2$ years of age. Of the 16 Bartonella spp.-infected PCR-positive cats, 15 were Bartonella spp.-seroreactive. Fourteen out of 15 Bartonella-seroreactive and PCR-positive cats had IFA antibody titers $\geq 1: 1024$ to one or more test antigens.

Hemotropic Mycoplasma spp. DNA was amplified by cPCR from $14 \%(19 / 135,95 \% \mathrm{CI}=8.2-19.9 \%)$ of the cats. Based on DNA sequencing, Mycoplasma haemofelis $(n=8)$, Candidatus M. haemominutum $(n=6)$, Candidatus M. turicensis $(n=4)$, and Mycoplasma wenyonii $(n=1)$ were identified. Anaplasma spp., Babesia, Cytauxzoon, Ehrlichia spp., Hepatozoon, and Theileria spp. were not detected in any of the samples studied.

For all DNA amplified by PCR, sequences were compared with sequences available in the GenBank database by nucleotide sequence homology using BLAST. Percentage of similarity, species, sequence description, and Genbank accession number are summarized in Tables 3, 4, and 5.

Based upon PCR results, 29 of 135 cats $(21.5 \%$, 95\% $\mathrm{CI}=14.6-28.4 \%)$ were infected with at least one bacterial organism. Seven cats $(5.2 \%, 95 \%$; $C I=1.4-8.9 \%)$ were co-infected with two pathogens based on molecular assays. Bartonella spp.-infected PCR-positive cats were more likely to be infected with hemotropic Mycoplasma spp. (37.5\%) than Bartonella spp. PCR-negative cats $(10.9 \%)$ (Fisher's exact test: $P=0.0115, \mathrm{OR}=4.89$, 95\% CI $=1.5-15.7)$.

Detailed clinical, serological, and PCR data for infected cats is summarized in Table 6. Two cats had gingivitis and one a purulent nasal discharge. There were no statistical associations when hemotropic Mycoplasma PCR results were compared with categorical clinical data or Bartonella spp. IFA serology results.

\section{Discussion}

The Bartonella spp. seroprevalence in this study was 80.7\%. Similar seroprevalence results (71.4\%) were reported in a study published in 2006 involving cats from the Barcelona area [31]. There has seemingly been little progress in preventing flea exposure among colony/stray and owned pet cats in this region. Despite the high Bartonella spp. seroprevalence, $84.4 \%$ of the seroreactive cats were apparently healthy. Gingivitis was the most frequent clinical finding among the sick cats. In addition, clinical abnormalities observed in Bartonella spp.-infected cats in this study were mild, highlighting the historically long 
Table 3 Bartonella spp. 16S-23S internal transcribed spacer sequences obtained by CPCR (primers Bspp. 325-1100) compared with sequences available in the GenBank database by nucleotide sequence homology using BLAST

\begin{tabular}{|c|c|c|c|c|}
\hline $\mathrm{ID}$ & GenBank accession no. & Bartonella spp. & Homology \% (bp) & $\begin{array}{l}\text { Compared sequence } \\
\text { GenBank accession } \\
\text { no. }\end{array}$ \\
\hline GUAB-14 & OK624784 & B. henselae & $100 \%(409 / 409)$ & $J Q 316963.1$ \\
\hline GUAB-27 & OK624785 & B. henselae & $99.45 \%(364 / 366)$ & EF209013.1 \\
\hline GUAB-35 & OK624786 & B. henselae & $100 \%(409 / 409)$ & JQ316963.1 \\
\hline GUAB-59 & OK624787 & B. clarridgeiae & $99.77 \%$ (429/430) & AB896695.1 \\
\hline GUAB-60 & OK624788 & B. henselae & $99.96 \%(585 / 587)$ & DQ529247.1 \\
\hline GUAB-75 & OK624789 & B. henselae & $100 \%(458 / 458)$ & KY464065.1 \\
\hline GUAB-77 & OK624790 & B. henselae & $100 \%(393 / 393)$ & HM042285.1 \\
\hline GUAB-78 & OK624791 & B. clarridgeiae & $100 \%(525 / 525)$ & AB896695.1 \\
\hline GUAB-79 & OK624792 & B. henselae & $100 \%(365 / 365)$ & DQ383228.1 \\
\hline GUAB-105 & OK624793 & B. clarridgeiae & $100 \%(509 / 509)$ & MN170544.1 \\
\hline
\end{tabular}

ID identification, \% percentage, $b p$ base pairs

Table 4 Bartonella spp. 16S-23S internal transcribed spacer sequences obtained by qPCR (primers Bspp 325-543) compared with sequences available in the GenBank database by nucleotide sequence homology using BLAST

\begin{tabular}{|c|c|c|c|c|}
\hline ID & GenBank accession no. & Species & Homology \% (bp) & $\begin{array}{l}\text { Compared sequence } \\
\text { GenBank accession } \\
\text { no. }\end{array}$ \\
\hline GUAB-14 & OK624794 & B. henselae & $99 \%(148 / 149)$ & AB896699.1 \\
\hline GUAB-35 & OK624795 & B. henselae & $100 \%(140 / 140)$ & Мт095053.1 \\
\hline GUAB-39 & OK624796 & B. henselae & $100 \%(148 / 148)$ & AB896699.1 \\
\hline GUAB-41 & OK624797 & B. henselae & $99 \%(167 / 168)$ & МT095054.1 \\
\hline GUAB-45 & OK624798 & B. henselae & $100 \%(151 / 151)$ & МT095050.1 \\
\hline GUAB-46 & OK624799 & B. henselae & $99 \%(148 / 149)$ & MT095048.1 \\
\hline GUAB-49 & OK624800 & B. henselae & $100 \%(144 / 144)$ & МT095053.1 \\
\hline GC-13 & OK624801 & B. koehlerae & $94 \%(120 / 127)$ & KX499345.1 \\
\hline
\end{tabular}

ID identification, \% percentage, $b p$ base pairs

and apparently efficient co-evolution of fleas, cats, and Bartonella spp., as well as the poor relationship between Bartonella seroreactivity and clinical status. In the present study, seroprevalence in owned and colony cats was $53 \%$ and $100 \%$, respectively. However, other studies performed in the Barcelona area found seroprevalence of $29.6 \%$ in owned pet cats [36] and $44 \%$ in shelter or colony cats when cats in both studies were tested only with a $B$. henselae assay [28]. Seroprevalence reported in cats from other areas of Spain has ranged from $24.7 \%$ in the Madrid area [29] to $50 \%$ described in a study that included several locations within the Mediterranean areas of Spain (Canary Islands, Galicia, and Madrid) [37].

To the best of our knowledge, this is the first study measuring antibodies against three different species of Bartonella and the first evidence of B. quintana and $B$. koehlerae seroreactivity in cats from Spain. In this study, $49.6 \%$ of seroreactive cats had high antibody titers against $B$. henselae ( $\geq 1: 1024)$, compared with a previous study from the same area carried out 17 years earlier that reported $23 \%$ seroreactivity, with maximum antibody titers of 1:512 [37]. Interestingly, the geometric mean antibody titer in the present study was 1:2050, compared to 1:256 in the previous study, which may reflect age-related differences in seroreactivity [31]. The mean age of cats in the present study and in the previous study was 1.2 and 4.4 years, respectively, suggesting that young cats may have higher antibody titers than older cats. In Europe, similar seroprevalence has been reported in Portugal (64.9\%) against Bartonella spp. [38] and in Germany (68.7\%) against B. henselae antigen [39]. Variations between studies are likely due to differences in the study populations (e.g., owned versus colony) and differences in Bartonella spp. prevalence among geographic areas, 
Table 5 Hemotropic Mycoplasma spp. 16S-23S internal transcribed spacer sequences obtained by cPCR compared with sequences available in the GenBank database by nucleotide sequence homology using BLAST

\begin{tabular}{|c|c|c|c|c|}
\hline ID & GenBank accession no. & Hemotropic Mycoplasma spp. & $\begin{array}{l}\text { Homology \% } \\
\text { (bp) }\end{array}$ & $\begin{array}{l}\text { Compared sequence } \\
\text { GenBank accession } \\
\text { no. }\end{array}$ \\
\hline G-UAB-27 & OK624802 & M. haemofelis & $93 \%(466 / 499)$ & MN240855.1 \\
\hline G-UAB-30 & OK624803 & M. haemofelis & $99 \%(508 / 509)$ & EU442638.1 \\
\hline G-UAB-37 & OK624804 & M. haemofelis & $100 \%(526 / 526)$ & KU645929.1 \\
\hline G-UAB-40 & OK624805 & Candidatus M. haemominutum & $95 \%(533 / 560)$ & KR905456.1 \\
\hline G-UAB-48 & OK624806 & M. haemofelis & $95 \%(496 / 524)$ & MG594502.1 \\
\hline G-UAB-49 & OK624807 & Candidatus M. haemominutum & $100 \%(547 / 547)$ & MT926039.1 \\
\hline G-UAB-58 & OK624808 & Candidatus M. haemominutum & $100 \%(508 / 508)$ & MN240865.1 \\
\hline G-UAB-60 & OK624809 & M. haemofelis & $99 \%(529 / 530)$ & KU645929.1 \\
\hline G-UAB-63 & OK624810 & Candidatus M. haemominutum & $99 \%(471 / 472)$ & KM275257.1 \\
\hline G-UAB-67 & OK624811 & Candidatus M. turicensis & $97 \%(499 / 512)$ & KY046312.1 \\
\hline G-UAB-70 & OK624812 & M. haemofelis & $100 \%(515 / 515)$ & KU645929.1 \\
\hline G-UAB-77 & OK624813 & M. wenyonii & $99 \%(539 / 546)$ & MT241310.1 \\
\hline G-UAB-78 & OK624814 & Candidatus M. turicensis & $100 \%(480 / 480)$ & MK632342.1 \\
\hline G-UAB-79 & OK624815 & Candidatus M. turicensis & $99 \%(461 / 466)$ & MK632342.1 \\
\hline G-UAB-88 & OK624816 & Candidatus M. haemominutum & $100 \%(534 / 534)$ & MT926039.1 \\
\hline G-UAB-94 & OK624817 & Candidatus M. haemominutum & $100 \%(546 / 546)$ & KR905457.1 \\
\hline G-UAB-109 & OK624818 & M. haemofelis & $100 \%(31 / 31)$ & MK632350.1 \\
\hline G-UAB-112 & OK624819 & M. haemofelis & $99 \%(529 / 530)$ & KU645929.1 \\
\hline G-UAB-115 & OK624820 & Candidatus M. turicensis & $99 \%(467 / 468)$ & EU789558.1 \\
\hline
\end{tabular}

ID identification, $\%$ percentage, $b p$ base pairs

differences in flea exposure, and differences in diagnostic techniques used among published studies $[29,40]$.

In this study, all Bartonella spp.-seroreactive cats had previously been exposed to fleas and/or ticks, in agreement with the well-known relationship between exposure to fleas and the transmission of Bartonella spp. infection in cats [41-44]. Although Bartonella transmission by ticks remains controversial, there is enough evidence (i.e., artificial membrane feeding system experiments, clinical and epidemiological studies in cats, dogs, and humans) to consider that Ixodes ricinus ticks can act as a vector for $B$. henselae [45-48]. The presence of Bartonella spp. DNA has also been documented in Rhipicephalus sanguineus ticks removed from cats and dogs $[44,49,50]$. However, less information is available regarding the potential role of $R$. sanguineus ticks or other tick species as potential vectors for Bartonella spp. transmission to cats, dogs, or humans $[44,51]$.

Several studies have assessed serological cross-reactivity between Bartonella species or strains in cats [52, 53], dogs [54], and humans [55, 56]. In our study, $65.2 \%$ of the cats examined had antibodies against all three Bartonella spp. IFA antigens. All cats that were seroreactive against B. koehlerae or B. quintana antigens were also seroreactive against $B$. henselae antigen. In addition, substantial to almost perfect agreement was found between the three species of Bartonella studied. Furthermore, the three cats infected with $B$. clarridgeiae had high antibody titers against $B$. henselae (1:2048-1:8192), B. quintana (1:256-1:1024), and B. koehlerae (1:512-1:2048). The present findings suggest serological cross-reactivity, as previously reported in cats $[49,50]$, or that cats were co-infected with several Bartonella spp. when infested with numerous fleas or both fleas and ticks. In this study, increasing the number of antigens by adding $B$. quintana and $B$. koehlerae to $B$. henselae did not increase the number of seroreactive cats. When experimentally infected with $B$. henselae or $B$. vinsonii subsp. berkhoffii, dogs naturally infected with $B$. koehlerae elicited a speciesspecific antibody response for the first 100 days of the study [57]. Differentiating cross-reactivity from co-exposures to multiple Bartonella spp., potentially occurring at multiple vector exposure time points among naturally exposed animals, often infested with numerous fleas and ticks, remains difficult to impossible with current diagnostic modalities.

The majority of young cats $\leq 2$ years were Bartonella spp--seroreactive. Furthermore, 14 of 16 PCR-seroreactive cats were $\leq 2$ years of age, although compared to cats older than 2 years, there was no significant difference. In agreement with previous studies, young cats were more likely to be bacteremic and seroreactive $[58,59]$. 


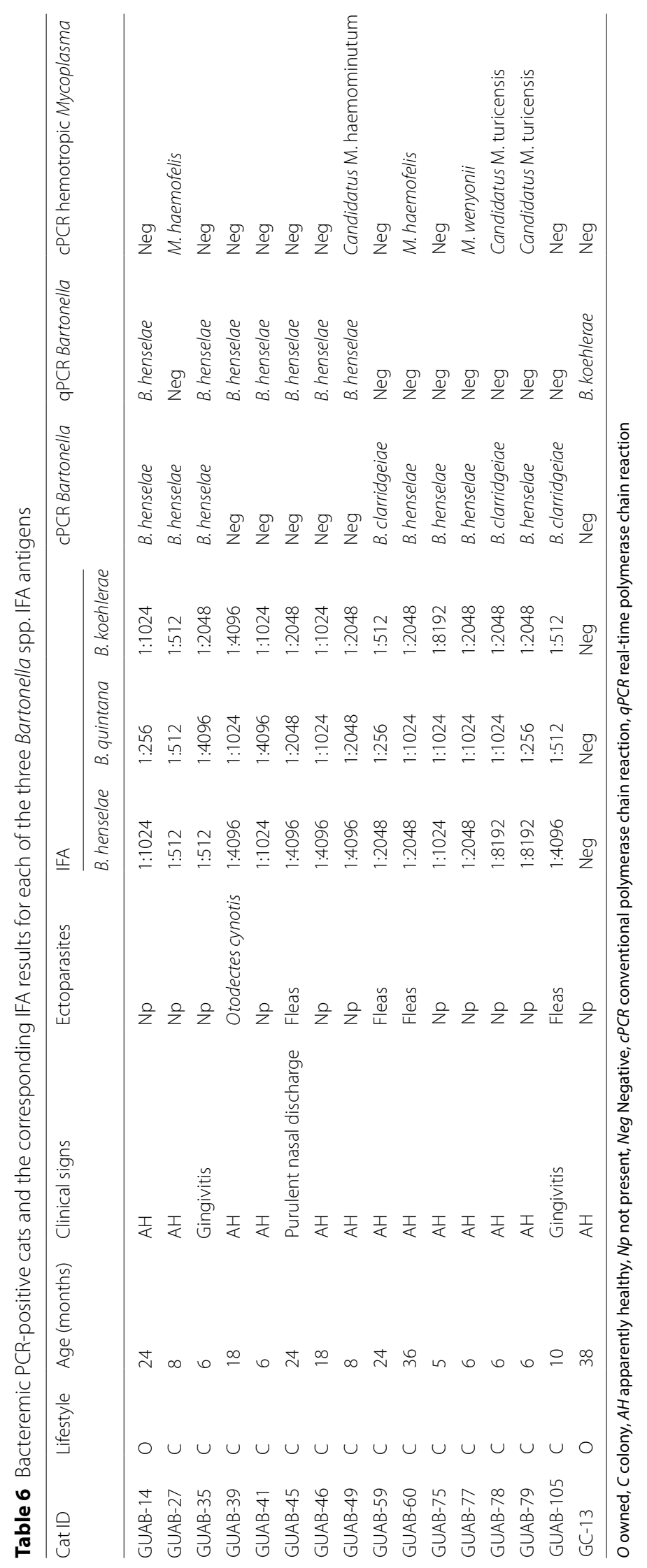


Moreover, in the present study, all cats with Bartonella spp. antibody titers ranging from 1:512 to 1:8192 were bacteremic, which is consistent with a previous study [58] and suggests that antibodies do not elicit effective immune elimination of bacteremia.

Bartonella spp. DNA was detected in $11.9 \%$ of the cats in this study. The most prevalent Bartonella species based on molecular analysis was $B$. henselae (8.9\%), also consistent with worldwide PCR data [3], followed by $B$. clarridgeiae (1.5\%) and B. koehlerae (0.7\%). The prevalence for $B$. henselae bacteremia has ranged from 0.3 to $38.3 \%$ in different areas of Spain $[28,29,36,60,61]$. Bartonella clarridgeiae infections have previously been reported in the Barcelona area, with similar bacteremia results ranging from 0.6 to $1 \%[31,60]$. A higher $B$. clarridgeiae bacteremia prevalence $(10.9 \%)$ was reported in northern Spain [62]. In Europe, bacteremic prevalence rates for various combinations of $B$. clarridgeiae, $B$. henselae, and $B$. koehlerae have ranged from 0.7 to 83.5\% [27, 63-65]. The differences in bacteremic prevalence are related to different climatic conditions, the cat population tested, and PCR techniques used, as well as intrinsic differences in bacteremic behavior linked to the microorganisms themselves. For example, it is possible that cats infected with $B$. koehlerae maintain a lower level of bacteremia than cats infected with $B$. henselae or $B$. clarridgeiae, as $B$. koehlerae is infrequently isolated or detected by PCR testing $[3,66]$. Despite this low bacteremic prevalence, cats are considered the main reservoir of B. koehlerae infection worldwide [67-69].

To the best of our knowledge, this is the first description of $B$. koehlerae infection in an apparently healthy cat from Spain, as has previously been reported in Greece [65], France [70], Israel [71], and the USA [67, 72]. Moreover, B. koehlerae infections have also been described in dogs from Israel [73], Spain [35, 74], and the USA [75], and infection has been diagnosed sporadically in humans from Israel [76] and the USA [77, 78]. Interestingly, $B$. koehlerae infection was not diagnosed in a large study in veterinary personnel from Spain, despite $41.6 \%$ of participants being $B$. koehlerae-seroreactive, using the same antigen as used in this study [22]. However, there is more worldwide evidence of $B$. koehlerae DNA in cat fleas, with prevalence exceeding $30 \%$ [79-83], suggesting that $B$. koehlerae infections in cats are potentially more common than studies have documented thus far [3]. In the present study, the $B$. koehlerae DNA-positive cat was seronegative against all three test antigens. In an experimental study, seroconversion was detected between of 7 to 15 days after $B$. koehlerae inoculation in cats [53]. The cats infected in that study had serological cross-reactivity with $B$. henselae antigens, but antibody titers against $B$. henselae were lower than $B$. koehlerae antibody titers
[53]. Therefore, we might hypothesize that this cat was recently infected or did not seroconvert despite being chronically infected, a phenomenon commonly described in bacteremic dogs [84]. Furthermore, it is important to highlight that in the present study, B. koehlerae was $94.49 \%$ identical to the B. koehlerae subsp. bothieri strain 1178 16S-23S ribosomal RNA intergenic spacer partial sequence as described previously [85], and therefore, this microorganism might be a new $B$. koehlerae strain or a closely related Bartonella species. For this reason, differences in antigenicity among $B$. koehlerae strains could make detection of antibodies in infected cats more difficult [85].

Although $B$. quintana seroprevalence was documented in this study, B. quintana has not previously been amplified from the blood of any cat in Spain. To the best of our knowledge, there is no previous molecular evidence documenting $B$. quintana infection in cats in Spain; however, $B$. quintana has been previously documented in sick humans $[86,87]$ and healthy humans in Spain [22, 88]. Nevertheless, B. quintana infection was documented from cat dental pulp in France [5] and from two bacteremic feral cats in the USA [6]. Failure to isolate or PCR-amplify B. quintana DNA from cats may reflect infrequent or low-level bacteremia, potentially requiring enrichment blood culture/PCR or testing at multiple time points to document potential B. quintana infection. Previous research has confirmed the ability of five Bartonella species including B. quintana to persist in C. felis [43], and B. quintana DNA has been amplified from cat fleas in France [80]. Therefore, fleas could be a potential alternative vector for $B$. quintana, although flea transmission has not yet been proven.

In the present study, the hemotropic Mycoplasma infection rate was $14 \%$, including the amplification and sequencing of $M$. haemofelis (5.9\%), Candidatus $M$. haemominutum (4.4\%), and Candidatus $M$. turicensis (3\%) DNA. Frequency and species distribution are similar and in agreement with previous studies from Spain, where hemotropic Mycoplasma prevalence of 7.8\% [28] and $12 \%$ [69] was reported from the Barcelona area and 10.6\% from Madrid [89]. Similar prevalence and species distribution have also been documented in Italy (11.6\% and 18.3\%) [90, 91] and Ireland (16.4\%) [92]. However, higher hemotropic Mycoplasma prevalence has been reported from Greece (26.4\%) [30] and Portugal (27.1\%) [93]. Therefore, hemotropic Mycoplasma spp. are widely distributed and prevalent among European cats. Furthermore, co-infection with hemotropic Mycoplasma and Bartonella spp. appears to be highly common among cats in the Barcelona area. Bartonella spp. and hemotropic Mycoplasma spp. co-infection prevalence was $4.4 \%$ in this study, compared with other cat studies from Italy 
that reported co-infection prevalence of 3\% [91] and $0.1 \%$ [90]. However, Bartonella and hemotropic Mycoplasma co-infection has not been documented in other feline [65] or canine [94] studies. Interestingly, Bartonella spp. and hemotropic Mycoplasma spp. co-infection has been sporadically reported in humans $[95,96]$. It remains unknown whether there are factors that predispose cats or humans to co-infection with Bartonella spp. and hemotropic Mycoplasma spp.; therefore, further studies are needed to elucidate these findings.

Surprisingly, and to the best of our knowledge, this is the first time that $M$. wenyonii DNA has been amplified from the blood of a cat worldwide and the first description of this hemoplasma in an animal from Spain. Mycoplasma wenyonii has been widely identified in bovines worldwide [97-99] but also sporadically documented in other ungulates such as water buffalo and red deer from central Europe [100], France [101], and Cuba [102]. The mode of transmission for the majority of hemotropic Mycoplasma species, including M. wenyonii, remains unknown [101]. One study reported potential vertical transmission for $M$. wenyonii. in bovines [103]. Interestingly, $M$. wenyonii DNA was confirmed in one wildcaught mosquito pool by DNA sequencing in the USA [104]. Those mosquitos were captured near feral cat colonies to specifically evaluate wild-caught mosquitoes for evidence of hemotropic Mycoplasma species DNA and to determine whether the feline hemoplasmas could be transmitted by Aedes aegypti mosquitoes in a laboratory setting. Laboratory transmission to naive cats was not documented, suggesting that this mosquito is not a biologically competent vector [104]. Further studies are needed to evaluate whether cats are infected with $M$. wenyonii accidentally or more commonly in areas where large ungulates such cows and cats might have close contact.

Anaplasma and Ehrlichia spp. DNA was not detected in this study. A low PCR prevalence (1\%) for these two tick-transmitted genera was previously reported in the Barcelona area [60]. In contrast, high molecular prevalence of Ehrlichia canis (9.9\%) and Anaplasma phagocytophilum (8.4\%) was described in cats from Madrid, Spain [29]. Anaplasma and Ehrlichia infections in cats are rare or sporadically documented worldwide $[90,105,106]$, in agreement with the present study. Furthermore, Babesia, Cytauxzoon, and Hepatozoon DNA was also not detected in the present study. These tick-associated protozoan infections in cats appear to be rare, and have only been sporadically documented in cats from Mediterranean regions [107-109], as was found in the present study.

\section{Conclusion}

In conclusion, Bartonella spp. and hemotropic Mycoplasma infections were found to be prevalent in cats residing in the Barcelona area, whereas no infection with Anaplasma, Ehrlichia, or Piroplasma species was detected by PCR testing. We report, for the first time, $B$. koehlerae infection in one apparently healthy cat in Spain. Co-infection with hemotropic Mycoplasma appears to be common in Bartonella-infected cats. Of note, M. wenyonii infection in cats is documented herein for the first time. Serological testing with the three Bartonella spp. antigens used in this study did not increase the overall seroprevalence as compared to IFA testing using only the $B$. henselae antigen. This and previous reports highlight the importance of combining serological and molecular diagnostic methods for the detection of Bartonella spp. infection. Future studies should focus on risk factors for acquiring co-infections with different Bartonella species and subspecies and whether co-infections might influence the clinical status and diagnosis of bartonellosis in cats. In addition, investigations are needed to better characterize the humoral immune response against Bartonella spp. to facilitate a better understanding of the immunological response to these bacteria in healthy and sick cats. Based upon our serology and PCR results, the risk of Bartonella and hemotropic Mycoplasma spp. transmission among cats, humans, and other animals in the Barcelona area may be substantial.

\section{Abbreviations \\ Bp: Base pair; DNA: Deoxyribonucleic acid; EDTA: Ethylenediaminetetraacetic acid; ELISA: Enzyme-linked immunosorbent assay; IFA: Indirect immunofluo- rescence assay; ITS: Internal transcribed spacer; $k$ : Cohen's kappa value; PBS: Phosphate-buffered saline; PCR: Polymerase chain reaction; CPCR: Conven- tional polymerase chain reaction; qPCR: Real time polymerase chain reaction; rRNA: Ribosomal ribonucleic acid; SE: Standard error.}

\section{Acknowledgements}

The authors thank all veterinarians and students who contributed to this study. In particular, we are grateful to Toni Richarson and Henry Marr (Intracellular Pathogens Research Laboratory College of Veterinary Medicine, North Carolina State University, NCSU), Diana Andrea Murillo, David Prandi, Iciar Martínez and Lourdes Alarcón (Universitat Autònoma de Barcelona, UAB) for the assistance with sampling and laboratory work.

\section{Authors' contributions}

LS and AA designed the research study. LS, RM and GM supervised technical work. $\mathrm{AA}, \mathrm{LS}$ and $\mathrm{MB}$ contributed with data analysis and interpretation. $\mathrm{AA}$ wrote the manuscript. LS and EB revised the manuscript. AA coordinated enrolment of cats, sampling and performed IFAs and PCRs. All authors read and approved the final manuscript.

\section{Funding}

This research was funded by Bayer Animal Health/Elanco. Publication of this manuscript has been sponsored by Elanco. 


\section{Availability of data and materials}

The datasets supporting the conclusions of this article are included within the article. All analyzed data are available from the corresponding author upon reasonable request. Representative sequences generated in this study were submitted to the GenBank under accession numbers OK624784-OK624820.

\section{Declarations}

\section{Ethics approval}

This study was conducted according to the guidelines of the Declaration of Helsinki, but ethical review and approval were waived for the study, due to non-invasive procedures and use of residual specimens. Furthermore, a signed consent form was obtained from the owner or the person in charge of the cats.

\section{Competing interests}

The authors declare no conflict of interest. Edward B. Breitschwerdt is a founder, shareholder and chief scientific officer for Galaxy Diagnostics, Research Triangle Park, North Carolina, USA. Galaxy Diagnostics was not involved in any aspect of this study. The funders had no role in the design of the study; in the collection, analyses, or interpretation of data; in the writing of the manuscript, or in the decision to publish the results.

\section{Author details}

1 Department of Animal Medicine and Surgery, Facultat de Veterinària, Universitat Autònoma de Barcelona, Cerdanyola del Valles, Spain. ${ }^{2}$ Department of Clinical Sciences and the Intracellular Pathogens Research Laboratory, Comparative Medicine Institute, College of Veterinary Medicine, North Carolina State University (NCSU), Raleigh, NC, USA. ${ }^{3}$ Department of Animal Health and Anatomy, Facultat de Veterinària, Universitat Autònoma de Barcelona, Cerdanyola del Valles, Spain.

Received: 4 June 2021 Accepted: 18 November 2021

Published online: 04 January 2022

\section{References}

1. Deng H, Le Rhun D, Buffet J-PR, Cotté V, Read A, Birtles RJ, et al. Strategies of exploitation of mammalian reservoirs by Bartonella species. Vet Res. 2012:43:15

2. Williams HM, Dittmar K. Expanding our view of Bartonella and its hosts: Bartonella in nest ectoparasites and their migratory avian hosts. Parasit Vectors. 2020:13:13

3. Álvarez-Fernández A, Breitschwerdt EB, Solano-Gallego L. Bartonella infections in cats and dogs including zoonotic aspects. Parasit Vectors. 2018;11:624.

4. Gurfield AN, Boulouis HJ, Chomel BB, Heller R, Kasten RW, Yamamoto K, et al. Coinfection with Bartonella clarridgeiae and Bartonella henselae and with different Bartonella henselae strains in domestic cats. J Clin Microbiol. 1997;35:2120.

5. La VD, Tran-Hung L, Aboudharam G, Raoult D, Drancourt M. Bartonella quintana in domestic cat. Emerg Infect Dis. 2005;11:1287-9.

6. Breitschwerdt EB, Maggi RG, Sigmon B, Nicholson WL. Isolation of Bartonella quintana from a woman and a cat following putative bite transmission. J Clin Microbiol. 2007;45:270-2.

7. Varanat M, Travis A, Lee W, Maggi RG, Bissett SA, Linder KE, et al. Recurrent osteomyelitis in a cat due to infection with Bartonella vinsonii subsp. berkhoffii genotype II. J Vet Intern Med. 2009;23:1273-7.

8. Joseph JL, Oxford EM, Santilli RA. Transient myocardial thickening in a Bartonella henselae positive cat. J Vet Cardiol. 2018;20:198-203.

9. Donovan T, Balakrishnan N, Carvalho Barbosa I, McCoy T, Breitschwerdt E, Fox P. Bartonella spp. as a possible cause or cofactor of feline endomyocarditis-left ventricular endocardial fibrosis complex. J Comp Pathol. 2018;162:29-42.

10. Tritschler C, Mizukami K, Raj K, Giger U. Increased erythrocytic osmotic fragility in anemic domestic shorthair and purebred cats. J Feline Med Surg. 2015;18:462-70.
11. Pennisi MG, Marsilio F, Hartmann K, Lloret A, Addie D, Belák S, et al. Bartonella species infection in cats: $A B C D$ guidelines on prevention and management. J Feline Med Surg. 2013;15:563-9.

12. Lappin MR, Breitschwerdt E, Brewer M, Hawley J, Hegarty B, Radecki S. Prevalence of Bartonella species antibodies and Bartonella species DNA in the blood of cats with and without fever. J Feline Med Surg. 2009;11:141-8.

13. Chomel BB, Wey AC, Kasten RW, Stacy BA, Labelle P. Fatal case of endocarditis associated with Bartonella henselae type I infection in a domestic cat. J Clin Microbiol. 2003;41:5337-9.

14. Varanat M, Broadhurst J, Linder KE, Maggi RG, Breitschwerdt EB. Identification of Bartonella henselae in 2 cats with pyogranulomatous myocarditis and diaphragmatic myositis. Vet Pathol. 2012;49:608-11.

15. Cheslock MA, Embers ME, Cheslock MA, Embers ME. Human bartonellosis: an underappreciated public health problem? Trop Med Infect Dis. 2019;4:69.

16. Breitschwerdt EB. Bartonellosis, one health and all creatures great and small. Vet Dermatol. 2017;28:96-e21.

17. La SB, Davoust B, Boni M, Raoult D. Lack of correlation between Bartonella DNA detection within fleas, serological results, and results of blood culture in a Bartonella-infected stray cat population. Clin Microbiol Infect. 2002;8:345-51.

18. Ficociello J, Bradbury C, Morris A, Lappin MR. Detection of Bartonella henselae IgM in serum of experimentally infected and naturally exposed cats. J Vet Intern Med. 2011;25:1264-9.

19. Lashnits E, Neupane P, Bradley JM, Richardson T, Thomas R, Linder KE, et al. Molecular prevalence of Bartonella, Babesia, and hemotropic Mycoplasma species in dogs with hemangiosarcoma from across the United States. PLoS One 2020;10;15(1):e0227234.

20. Lashnits E, Correa M, Hegarty BC, Birkenheuer A, Breitschwerdt EB. Bartonella Seroepidemiology in dogs from North America, 2008-2014. J Vet Intern Med. 2018;32(1):222-31.

21. Maurin M, Rolain JM, Raoult D. Comparison of in-house and commercial slides for detection by immunofluorescence of immunoglobulins $G$ and $\mathrm{M}$ against Bartonella henselae and Bartonella quintana. Clin Vaccine Immunol. 2002;9:1004-9.

22. Oteo JA, Maggi R, Portillo A, Bradley J, García-Álvarez L, San-Martín $M$, et al. Prevalence of Bartonella spp. by culture, PCR and serology, in veterinary personnel from Spain. Parasit Vectors BioMed Central. 2017:10:553.

23. McGill S, Wesslén L, Hjelm E, Holmberg M, Auvinen MK, Berggren K, et al. Bartonella spp. seroprevalence in healthy Swedish blood donors. Scand J Infect Dis. 2005;37:723-30.

24. Neupane P, Sevala S, Balakrishnan N, Marr H, Wilson J, Maggi R, et al. Validation of Bartonella henselae western immunoblotting for serodiagnosis of bartonelloses in dogs. J Clin Microbiol. 2020;58(4):e0133519.

25. Chomel BB, Kasten RW. Bartonellosis, an increasingly recognized zoonosis. J Appl Microbiol. 2010;109:743-50.

26. Bergh K, Bevanger L, Hanssen I, Loseth K. Low prevalence of Bartonella henselae infections in Norwegian domestic and feral cats. APMIS. 2002;110:309-14.

27. Pennisi MG, La Camera E, Giacobbe L, Orlandella BM, Lentini V, Zummo $S$, et al. Molecular detection of Bartonella henselae and Bartonella clarridgeiae in clinical samples of pet cats from Southern Italy. Res Vet Sci. 2010:88:379-84.

28. Ravicini S, Pastor J, Hawley J, Brewer M, Castro-López J, Beall M, et al. Prevalence of selected infectious disease agents in stray cats in Catalonia, Spain. JFMS Open Rep. 2016. https://doi.org/10.1177/2055116916 634109.

29. Aylló T, Paulo P, Diniz VP, Breitschwerdt EB, Villaescusa A, RodríguezFranco F, et al. Vector-borne diseases in client-owned and stray cats from Madrid, Spain. Vector Borne Zoonotic Dis. 2012;12(2):143-50.

30. Attipa C, Papasouliotis K, Solano-Gallego L, Baneth G, Nachum-Biala Y, Sarvani E, et al. Prevalence study and risk factor analysis of selected bacterial, protozoal and viral, including vector-borne, pathogens in cats from Cyprus. Parasit Vectors. 2017;10:130.

31. Solano-Gallego L, Hegarty B, Espada Y, Llull J, Breitschwerdt E. Serological and molecular evidence of exposure to arthropod-borne organisms in cats from northeastern Spain. Vet Microbiol. 2006;118:274-7. 
32. Álvarez-Fernández A, Baxarias M, Prandi D, Breitschwerdt EB, SolanoGallego L. Bartonella henselae antibodies in serum and oral fluid specimens from cats. Pathogens. 2021;1-11.

33. Solano-Gallego L, Di Filippo L, Ordeix L, Planellas M, Roura X, Altet L, et al. Early reduction of Leishmania infantum-specific antibodies and blood parasitemia during treatment in dogs with moderate or severe disease. Parasit Vectors. 2016;9(1):235.

34. Breitschwerdt EB, Hegarty BC, Qurollo BA, Saito TB, Maggi RG, Blanton LS, et al. Intravascular persistence of Anaplasma platys, Ehrlichia chaffeensis, and Ehrlichia ewingii DNA in the blood of a dog and two family members. Parasit Vectors. 2014;1(7):298.

35. Tabar M-D, Altet L, Maggi RG, Altimira J, Roura X. First description of Bartonella koehlerae infection in a Spanish dog with infective endocarditis. Parasit Vectors. 2017;10:247

36. Pons I, Sanfeliu I, Quesada M, Anton E, Sampere M, Font B, et al. Prevalence of Bartonella henselae in cats in Catalonia, Spain. Am J Trop Med Hyg. 2005;72:453-7.

37. Gracia MJ, Marcén JM, Pinal R, Calvete C, Rodes D. Prevalence of Rickettsia and Bartonella species in Spanish cats and their fleas. J Vector Ecol. 2015:40:233-9.

38. Alves AS, Milhano N, Santos-Silva M, Santos AS, Vilhena M, De Sousa R. Evidence of Bartonella spp., Rickettsia spp. and Anaplasma phagocytophilum in domestic, shelter and stray cat blood and fleas, Portugal. Clin Microbiol Infect. 2009;15:1-3.

39. Mietze A, Morick D, Köhler H, Harrus S, Dehio C, Nolte I, et al. Combined MLST and AFLP typing of Bartonella henselae isolated from cats reveals new sequence types and suggests clonal evolution. Vet Microbiol. 2011;148:238-45.

40. Bradbury CA, Lappin MR. Evaluation of topical application of $10 \%$ imidacloprid-1\% moxidectin to prevent Bartonella henselae transmission from cat fleas. J Am Vet Med Assoc. 2010;236:869-73.

41. Tsai YL, Chang CC, Te CS, Chomel BB. Bartonella species and their ectoparasites: selective host adaptation or strain selection between the vector and the mammalian host? Comp Immunol Microbiol Infect Dis. 2011:34:299-314.

42. Gutiérrez $R$, Nachum-Biala $Y$, Harrus $S$. The relations between the presence and bacterial loads of Bartonella species in the cat and cat flea (Ctenocephalides felis), under natural conditions. Appl Environ Microbiol. 2015;81:5613-21.

43. Bouhsira E, Ferrandez Y, Liu M, Franc M, Boulouis HJ, Biville F. Ctenocephalides felis an in vitro potential vector for five Bartonella species. Comp Immunol Microbiol Infect Dis. 2013:36:105-11.

44. Wechtaisong W, Bonnet SI, Lien YY, Te CS, Tsai YL. Transmission of Bartonella henselae within Rhipicephalus sanguineus: data on the potential vector role of the tick. PLoS Negl Trop Dis. 2020;14:1-14.

45. Podsiadly E, Chmielewski T, Sochon E, Tylewska-Wierzbanowska S. Bartonella henselae in Ixodes ricinus ticks removed from dogs. Vector Borne Zoonotic Dis. 2007;7:189-92.

46. Billeter SA, Levy MG, Chomel BB, Breitschwerdt EB. Vector transmission of Bartonella species with emphasis on the potential for tick transmission. Med Vet Entomol. 2008;22:1-15.

47. Regier Y, Ballhorn W, Kempf VAJ. Molecular detection of Bartonella henselae in 11 Ixodes ricinus ticks extracted from a single cat. Parasite Vectors. 2017;10(1):105.

48. Król N, Militzer N, Stöbe E, Nijhof AM, Pfeffer M, Kempf VAJ, et al. Microorganisms evaluating transmission paths for three different Bartonella spp. in Ixodes ricinus ticks using artificial feeding. Microorganisms. 2021;9(5):901.

49. Tsai YL, Lin CC, Chomel BB, Te CS, Tsai KH, Wu WJ, et al. Bartonella infection in shelter cats and dogs and their ectoparasites. Vector-Borne Zoonotic Dis. 2011;11:1023-30.

50. Pennisi M-G, Persichetti M-F, Serrano L, Altet L, Reale S, Gulotta L, et al. Ticks and associated pathogens collected from cats in Sicily and Calabria (Italy). Parasit Vectors. 2015;8:512.

51. Billeter SA, Kasten RW, Killmaster LF, Breitschwerdt EB, Levin ML, Levy $M G$, et al. Experimental infection by capillary tube feeding of Rhipicephalus sanguineus with Bartonella vinsonii subspecies berkhoffii. Comp Immunol Microbiol Infect Dis. 2012;35:9-15.

52. Baneth G, Kordick DL, Hegarty BC, Breitschwerdt EB. Comparative seroreactivity to Bartonella henselae and Bartonella quintana among cats from Israel and North Carolina. Vet Microbiol. 1996:50:95-103.
53. Yamamoto K, Chomel BB, Kasten RW, Hew CM, Weber DK, Lee WI, et al. Experimental infection of domestic cats with Bartonella koehlerae and comparison of protein and DNA profiles with those of other Bartonella species infecting felines. J Clin Microbiol. 2002;40:466-74.

54. Hegarty BC, Bradley JM, Lappin MR, Balakrishnan N, Mascarelli PE, Breitschwerdt EB. Analysis of seroreactivity against cell culture-derived Bartonella spp. antigens in dogs. J Vet Intern Med. 2014;28:38-41.

55. Tea A, Alexiou-Daniel S, Arvanitidou M, Diza E, Antoniadis A. Occurrence of Bartonella henselae and Bartonella quintana in a healthy Greek population. Am J Trop Med Hyg. 2003;68:554-6.

56. Vermeulen MJ, Verbakel H, Notermans DW, Reimerink JHJ, Peeters MF. Evaluation of sensitivity, specificity and cross-reactivity in Bartonella henselae serology. J Med Microbiol. 2010;59(6):743-5.

57. Neupane P, Hegarty BC, Marr HS, Maggi RG, Birkenheuer AJ, et al. Evaluation of cell culture-grown Bartonella antigens in immunofluorescent antibody assays for the serological diagnosis of bartonellosis in dogs. J Vet Intern Med. 2018;32(6):1958-64.

58. Chomel BB, Abbott RC, Kasten RW, Floyd-Hawkins KA, Kass PH, Glaser CA, et al. Bartonella henselae prevalence in domestic cats in California: risk factors and association between bacteremia and antibody titers. J Clin Microbiol. 1995;33:2445-50.

59. Fleischman DA, Chomel BB, Kasten RW, Stuckey MJ, Scarlet J, Liu H, et al. Bartonella Infection among cats adopted from a San Francisco Shelter, Revisited. Appl Environ Microbiol. 2015;81:6446-50.

60. Tabar MD, Altet L, Francino O, Sánchez A, Ferrer L, Roura X. Vector-borne infections in cats: molecular study in Barcelona area (Spain). Vet Parasitol. 2008:151:332-6.

61. Alamán VM, Simón VC, Fuertes NH, Unzueta GA, Flores SB, Halaihel KN Molecular epidemiology of Bartonella henselae in stray and sheltered cats of Zaragoza, Spain. Rev Esp Salud Publica. 2016;90:1-11.

62. Gil H, Escudero R, Pons I, Rodríguez-Vargas M, García-Esteban C, Rodríguez-Moreno I, et al. Distribution of Bartonella henselae variants in patients, reservoir hosts and vectors in Spain. PLoS ONE. 2013;8:e68248

63. Silaghi C, Knaus M, Rapti D, Kusi I, Shukullari E, Hamel D, et al. Survey of Toxoplasma gondii and Neospora caninum, haemotropic Mycoplasmas and other arthropod-borne pathogens in cats from Albania. Parasit Vectors. 2014;7:62.

64. Bennett AD, Gunn-Moore DA, Brewer M, Lappin MR. Prevalence of Bartonella species, haemoplasmas and Toxoplasma gondii in cats in Scotland. J Feline Med Surg. 2011;13:553-7.

65. Mylonakis ME, Schreeg M, Chatzis MK, Pearce J, Marr HS, Saridomichelakis MN, et al. Molecular detection of vector-borne pathogens in Greek cats. Ticks Tick Borne Dis. 2018;9:171-5.

66. Chomel BB, Boulouis H-J, Maruyama S, Breitschwerdt EB. Bartonella spp. in pets and effect on human health. Emerg Infect Dis. 2006;12:389-94.

67. Droz S, Chi B, Horn E, Steigerwalt AG, Whitney AM, Brenner DJ. Bartonella koehlerae sp. nov., isolated from cats. J Clin Microbiol. 1999;37:1117-22.

68. Müller A, Walker R, Bittencourt P, Machado RZ, Benevenute JL, Do Amaral RB, et al. Prevalence, hematological findings and genetic diversity of Bartonella spp. in domestic cats from Valdivia, Southern Chile. Parasitology. 2017;144:773-82.

69. Assarasakorn S, Veir JK, Hawley JR, Brewer MM, Morris AK, Hill AE, et al. Prevalence of Bartonella species, hemoplasmas, and Rickettsia felis DNA in blood and fleas of cats in Bangkok, Thailand. Res Vet Sci. 2012;93:1213-6.

70. Rolain JM, Fournier PE, Raoult D, Bonerandi JJ. First isolation and detection by immunofluorescence assay of Bartonella koehlerae in erythrocytes from a French cat. J Clin Microbiol. 2003;41 (8):4001-2.

71. Gutiérrez R, Morick D, Gross I, Winkler R, Abdeen Z, Harrus S. Bartonellae in domestic and stray cats from Israel: comparison of bacterial cultures and high-resolution melt real-time PCR as diagnostic methods. VectorBorne Zoonotic Dis. 2013;13:857-64.

72. Qurollo BA, Balakrishnan N, Cannon CZ, Maggi RG, Breitschwerdt EB. Co-infection with Anaplasma platys, Bartonella henselae, Bartonella koehlerae and "Candidatus Mycoplasma haemominutum" in a cat diagnosed with splenic plasmacytosis and multiple myeloma. J Feline Med Surg. 2014;16:713-20.

73. Ohad DG, Morick D, Avidor B, Harrus S. Molecular detection of Bartonella henselae and Bartonella koehlerae from aortic valves of Boxer dogs with infective endocarditis. Vet Microbiol. 2010;141:182-5. 
74. Roura X, Santamarina G, Tabar M-D, Francino O, Altet L. Polymerase chain reaction detection of Bartonella spp. in dogs from Spain with blood culture-negative infectious endocarditis. J Vet Cardiol. 2018;20(4):267-75.

75. Golly E, Breitschwerdt EB, Balakrishnan N, Moore D, Bizikova P. Bartonella henselae, Bartonella koehlerae and Rickettsia rickettsii seroconversion and seroreversion in a dog with acute-onset fever, lameness, and lymphadenopathy followed by a protracted disease course. Vet Parasitol Reg Stud Reports. 2017;7:19-24

76. Avidor B, Graidy M, Efrat G, Leibowitz C, Shapira G, Schattner A, et al. Bartonella koehlerae, a new cat-associated agent of culture-negative human endocarditis. J Clin Microbiol. 2004;42:3462-8.

77. Mozayeni BR, Maggi RG, Bradley JM, Breitschwerdt EB. Rheumatological presentation of Bartonella koehlerae and Bartonella henselae bacteremias. Medicine. 2018;97(17):e0465

78. Breitschwerdt EB, Mascarelli PE, Schweickert LA, Maggi RG, Hegarty BC, Bradley JM, et al. Hallucinations, sensory neuropathy, and peripheral visual deficits in a young woman infected with Bartonella koehlerae. J Clin Microbiol. 2011;49:3415-7.

79. Marié JL, Fournier PÉ, Rolain JM, Briolant S, Davoust B, Raoult D. Molecular detection of Bartonella quintana, B. elizabethae, B. koehlerae, B. doshiae, B. taylorii, and Rickettsia felis in rodent fleas collected in Kabul, Afghanistan. Am J Trop Med Hyg. 2006;74:436-9.

80. Rolain JM, Franc M, Davoust B, Raoult D. Molecular detection of Bartonella quintana, B. koehlerae, B. henselae, B. clarridgeiae, Rickettsia felis, and Wolbachia pipientis in cat fleas, France. Emerg Infect Dis. 2003:9:338-42.

81. Azrizal-Wahid N, Sofian-Azirun M, Low VL. Flea-borne pathogens in the cat flea Ctenocephalides felis and their association with mtDNA diversity of the flea host. Comp Immunol Microbiol Infect Dis. 2021;75:101621.

82. Mifsud M, Takacs N, Gyurkovszky M, Solymosi N, Farkas R. Detection of flea-borne pathogens from cats and fleas in a maltese shelter. VectorBorne Zoonotic Dis. 2020;20:529-34.

83. Müller A, Rodríguez E, Walker R, Bittencourt P, Pérez-Macchi S, Gonçalves LR, et al. Occurrence and genetic diversity of Bartonella spp. (Rhizobiales: Bartonellaceae) and Rickettsia spp. (Rickettsiales: Rickettsiaceae) in cat fleas (Siphonaptera: Pulicidae) from Chile. J Med Entomol. 2018;55:1627-32.

84. Pérez C, Maggi RG, Diniz PPVP, Breitschwerdt EB. Molecular and serological diagnosis of Bartonella infection in 61 dogs from the United States. J Vet Intern Med. 2011;25:805-10.

85. Chomel BB, Molia S, Kasten RW, Borgo GM, Stuckey MJ, Maruyama S, et al. Isolation of Bartonella henselae and two new Bartonella subspecies, Bartonellakoehlerae subspecies boulouisii subsp nov and Bartonella koehlerae subspecies bothieri subsp. nov. from free-ranging Californian mountain lions and bobcats. PLoS ONE. 2016:11(3):e01482992016.

86. Marín M, Muñoz P, Sánchez M, Del Rosal M, Alcalá L, Rodríguez-Créixems $M$, et al. Molecular diagnosis of infective endocarditis by real-time broad-range polymerase chain reaction (PCR) and sequencing directly from heart valve tissue. Medicine. 2007;86:195-202.

87. Sala M, Font B, Sanfeliu I, Quesada M, Ponts I, Segura F. Bacillary angiomatosis caused by Bartonella quintana. Ann N Y Acad Sci. 2005;1063:302-7.

88. Portillo A, Maggi R, Oteo JA, Bradley J, García-álvarez L, San-martín M, et al. Bartonella spp. prevalence (serology, culture, and PCR) in sanitary workers in La Rioja Spain. Pathogens. 2020;9(3):189.

89. Díaz-Regañón D, Villaescusa A, Ayllón T, Rodríguez-Franco F, GarcíaSancho M, Agulla B, et al. Epidemiological study of hemotropic Mycoplasmas (hemoplasmas) in cats from central Spain. Parasit Vectors. 2018;11(1):140.

90. Latrofa MS, latta R, Toniolo F, Furlanello T, Ravagnan S, Capelli G, et al. A molecular survey of vector-borne pathogens and haemoplasmas in owned cats across Italy. Parasit Vectors. 2020;13(1):116.

91. Persichetti MF, Pennisi MG, Vullo A, Masucci M, Migliazzo A, SolanoGallego L. Clinical evaluation of outdoor cats exposed to ectoparasites and associated risk for vector-borne infections in southern Italy. Parasit Vectors. 2018;11(1):136.

92. Juvet F, Lappin MR, Brennan S, Mooney CT. Prevalence of selected infectious agents in cats in Ireland. J Feline Med Surg. 2010;12:476-82.
93. Duarte A, Marques V, Correia JHD, Neto I, Bráz BS, Rodrigues C, et al. Molecular detection of haemotropic Mycoplasma species in urban and rural cats from Portugal. J Feline Med Surg. 2015;17:516-22.

94. Mascarelli PE, Tartara GP, Pereyra NB, Maggi RG. Detection of Mycoplasma haemocanis, Mycoplasma haematoparvum, Mycoplasma suis and other vector-borne pathogens in dogs from Córdoba and Santa Fé. Argentina Parasit Vectors. 2016;9:642.

95. Sykes JE, Lindsay LAL, Maggi RG, Breitschwerdt EB. Human coinfection with Bartonella henselae and two hemotropic Mycoplasma variants resembling Mycoplasma ovis. J Clin Microbiol. 2010;48:3782-5.

96. Dos Santos AP, Dos Santos RP, Biondo AW, Dora JM, Goldani LZ, De Oliveira ST, et al. Hemoplasma infection in HIV-positive patient. Brazil Emerg Infect Dis. 2008;14:1922-4.

97. Meli ML, Willi B, Dreher UM, Cattori V, Knubben-Schweizer G, Nuss K, et al. Identification, molecular characterization, and occurrence of two bovine hemoplasma species in Swiss cattle and development of real-time TaqMan quantitative PCR assays for diagnosis of bovine hemoplasma infections. J Clin Microbiol. 2010;48:3563-8.

98. Tagawa M, Matsumoto K, Inokuma H. Molecular detection of Mycoplasma wenyonii and "Candidatus Mycoplasma haemobos" in cattle in Hokkaido. Japan Vet Microbiol. 2008;132:177-80.

99. Stevanović O, Jurković D, Polkinghorne A, Ćeleš A, llić T, Dimitrijević $\mathrm{S}$, et al. Molecular detection of Babesia divergens and Mycoplasma wenyonii infection in cattle from Bosnia And Herzegovina. Parasitol Res. 2020;119:1423-7.

100. Hornok S, Sugár L, Fernández de Mera IG, de la Fuente J, Horváth G, Kovács T, et al. Tick- and fly-borne bacteria in ungulates: The prevalence of Anaplasma phagocytophilum, haemoplasmas and rickettsiae in water buffalo and deer species in Central Europe, Hungary. BMC Vet Res. 2018;14(1):98.

101. Nouvel LX, Hygoneng MC, Catays G, Martinelli E, Le Page P, Collin É, et al. First detection of Mycoplasma wenyonii in France: Identification, evaluation of the clinical impact and development of a new specific detection assay. Comp Immunol Microbiol Infect Dis. 2019;63:148-53.

102. Díaz-Sánchez AA, Corona-González B, Meli ML, Álvarez DO, Cañizares EV, Rodríguez OF, et al. First molecular evidence of bovine hemoplasma species (Mycoplasma spp.) in water buffalo and dairy cattle herds in Cuba. Parasite Vectors. 2019;12(1):78.

103. Niethammer FM, Ade J, Hoelzle LE, Schade B. Hemotrophic Mycoplasma in Simmental cattle in Bavaria: prevalence, blood parameters, and transplacental transmission of "Candidatus Mycoplasma haemobos" and Mycoplasma wenyonii. Acta Vet Scand. 2018;60(1):74.

104. Reagan KL, Clarke LL, Hawley JR, Lin P, Lappin MR. Assessment of the ability of Aedes species mosquitoes to transmit feline Mycoplasma haemofelis and 'Candidatus Mycoplasma haemominutum'. J Feline Med Surg. 2021;19:798-802.

105. Guimarães A, Raimundo JM, Rodrigues RB, Peixoto MP, Santos HA, André MR, et al. Ehrlichia spp. infection in domestic cats from Rio de Janeiro State, southeast Brazil. Rev Bras Parasitol Vet. 2019;28:180-5.

106. Schäfer I, Kohn B. Anaplasma phagocytophilum infection in cats: a literature review to raise clinical awareness. J Feline Med Surg. 2020;22(5):428-41.

107. Morganti G, Veronesi F, Stefanetti V, Di Muccio T, Fiorentino E, Diaferia M, et al. Emerging feline vector-borne pathogens in Italy. Parasites Vectors. 2019:12:193.

108. Carli E, Trotta M, Bianchi E, Furlanello T, Caldin M, Pietrobelli M, et al. Cytauxzoon sp. infection in two free ranging young cats: clinicopathological findings, therapy and follow up. Turkiye Parazitol Derg. 2014;38:185-9.

109. Carli E, Trotta M, Chinelli R, Drigo M, Sinigoi L, Tosolini P, et al. Cytauxzoon sp. infection in the first endemic focus described in domestic cats in Europe. Vet Parasitol. 2012;183:343-52.

\section{Publisher's Note}

Springer Nature remains neutral with regard to jurisdictional claims in published maps and institutional affiliations. 